\title{
Simple Microwave-Assisted Synthesis of Carbon Nanotubes Using Polyethylene as Carbon Precursor
}

\author{
N. Kure, ${ }^{1,2}$ M. N. Hamidon, ${ }^{1,3}$ S. Azhari, ${ }^{3}$ N. S. Mamat,,${ }^{3,4}$ H. M. Yusoff, ${ }^{5}$ \\ B. M. Isa, ${ }^{1}$ and Z. Yunusa ${ }^{3}$ \\ ${ }^{1}$ Department of Electrical and Electronic Engineering, Universiti Putra Malaysia 43400 Serdang, Selangor, Malaysia \\ ${ }^{2}$ Department of Physics, Kaduna State University, Tafawa Balewa Way, PMB 2339, Kaduna, Nigeria \\ ${ }^{3}$ Institute of Advanced Technology, Universiti Putra Malaysia, 43400 Serdang, Selangor, Malaysia \\ ${ }^{4}$ Department of Physics, Universiti Putra Malaysia, 43400 Serdang, Selangor, Malaysia \\ ${ }^{5}$ Department of Chemical and Environmental Engineering, Universiti Putra Malaysia, 43400 Serdang, Selangor, Malaysia
}

Correspondence should be addressed to N. Kure; kurenicodemus@yahoo.com

Received 16 July 2016; Revised 10 November 2016; Accepted 13 November 2016; Published 2 January 2017

Academic Editor: Andrew R. Barron

Copyright (C) 2017 N. Kure et al. This is an open access article distributed under the Creative Commons Attribution License, which permits unrestricted use, distribution, and reproduction in any medium, provided the original work is properly cited.

In this work, a quick and effective method to synthesize carbon nanotubes (CNTs) is reported; a commercial microwave oven of $600 \mathrm{~W}$ at $2.45 \mathrm{GHz}$ was utilized to synthesize CNTs from plasma catalytic decomposition of polyethylene. Polyethylene and silicon substrate coated with iron (III) nitrate were placed in the reaction chamber to form the synthesis stock. The CNTs were synthesized at $750^{\circ} \mathrm{C}$ under atmospheric pressure of $0.81 \mathrm{mbar}$. Raman spectroscopy and field emission scanning electron microscope revealed the quality and entangled bundles of mixed CNTs from which the diameters of the CNTs were calculated to be between 1.03 and $25.00 \mathrm{~nm}$. High resolution transmission electron microscope further showed that the CNTs obtained by this method are graphitized. Energy dispersive X-ray analysis and thermogravimetric analysis revealed above $98 \%$ carbon purity.

\section{Introduction}

The synthesis of carbon nanotubes (CNTs) using waste materials has received much attention in recent years. This increased focus was due to synthesis techniques becoming more expensive and time consuming. The microwaveassisted synthesis technique has attracted much attention over the conventional techniques such as chemical vapor deposition (CVD), laser ablation, Hipco, and arc discharge due to its advantages, for instance, volumetric heating, rapid reaction time, economical and environmental friendliness [1]. The basic principle of microwave heating is the transfer of electromagnetic energy to thermal energy within the material used, due to molecular interaction with the electromagnetic field. It is believed that materials are heated differently by microwaves [2]. Carbon materials have the ability to absorb microwave energy and convert it to thermal energy (dielectric tangent loss) at $2.45 \mathrm{GHz}$ [3]. Thus, the need for cost effective and rapid synthesis has become important.
Innovative approach was employed in this study, with an attempt to develop a technique that can synthesize CNTs economically within short time by using commercial microwave oven in a batch synthesis process $[1,2,4,5]$. Solid carbon source (polyethylene) was used as starting material unlike the liquid-gaseous carbon source in other techniques. To date, solid carbon materials are good microwave absorbers due to their dielectric properties which makes them conducting polymers and gives them crucial roles in CNTs growth [4]. The plasma created as a result of electromagnetic interactions provides the required temperature for catalytic decomposition of the starting materials.

\section{Experimental}

The commercial microwave oven was modified with quartz tube of volume $1860 \mathrm{~mL}$. Polyethylene $\left(\left(\mathrm{C}_{2} \mathrm{H}_{4}\right)_{n}\right)$ resins were used as carbon source. The carbon source has a very high 


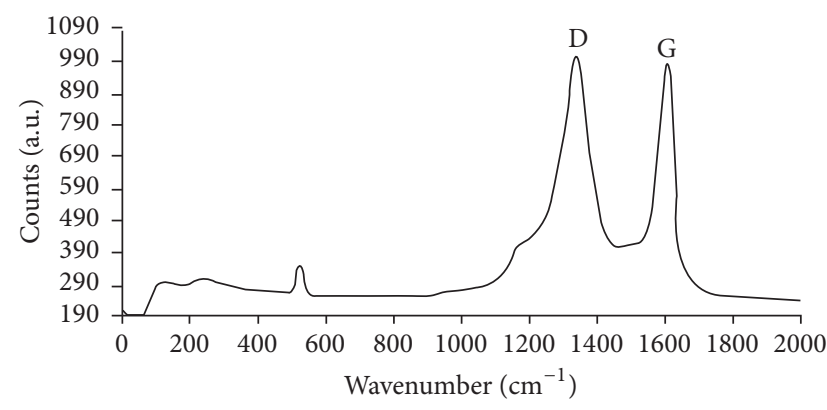

(a)

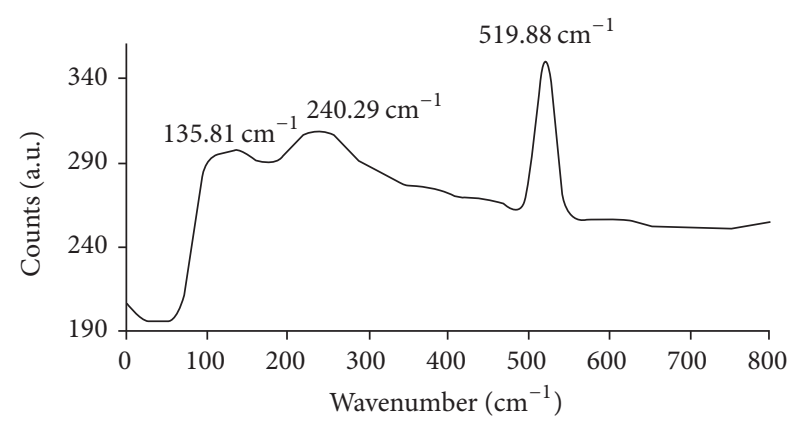

(b)

FIgURE 1: (a) Raman spectra showing Raman peaks of the CNTs. (b) Raman spectra showing RBM mode of CNTs.

dielectric tangent loss at $2.45 \mathrm{GHz}$ [3] which enables fast decomposition into carbon species over the catalyst nanoparticles. Iron (III) nitrate nonahydrate $\left(\mathrm{Fe}\left(\mathrm{NO}_{3}\right)_{3} \cdot 9 \mathrm{H}_{2} \mathrm{O}\right)$ of $1 \mathrm{~g}$ was diluted in $50 \mathrm{~mL}$ of ethanol as catalyst. The catalyst was impregnated on the silicon substrate using drop casting process and was calcinated in a furnace at $200^{\circ} \mathrm{C}$ for 30 minutes to evaporate the ethanol residue [6]. Polyethylene resins of $100 \mathrm{mg}$ were placed on aluminum foil of $2.50 \mathrm{~cm} \times$ $2.50 \mathrm{~cm}$. The aluminum foil and coated substrate were both placed in the reaction chamber. Pressure inside the chamber was reduced to $0.81 \mathrm{mbar}$ to initiate plasma formation via microwave irradiation on the tube, thus increasing growth rate and stabilization of plasma.

The carbon decomposition started few seconds after the formation of plasma. A bright purple color was observed which changed as soon as the decomposition process started [5]. A K-type thermocouple was used to measure the synthesis temperature at $750^{\circ} \mathrm{C}$. The final products were allowed to reach room temperature and then collected for characterizations. The time this method took from turning on the microwave till collecting the sample was about 1 hour. The Raman spectroscopy employed was Witec Alpha 300R with laser excitation wavelength of $532 \mathrm{~nm}$. Field emission scanning electron microscopy (FESEM) was carried out on a Joel JSM-7600F. High resolution transmission electron microscopy (HRTEM) images and energy dispersive X-ray (EDX) analysis were obtained using a FEI Tecnai G2 F20 XTWIN. Thermogravimetric analysis (TGA) was carried out using Mettler thermobalance TG-50 in a Mettler TA-4000 System, with temperature ranging from $30^{\circ} \mathrm{C}$ to $1000^{\circ} \mathrm{C}$ with interval of $10^{\circ} \mathrm{C} / \mathrm{min}$ under oxygen gas with flow rate of $50 \mathrm{~mL} / \mathrm{min}$.

\section{Results and Discussion}

The Raman analysis showed in Figure 1(a) indicates two prominent peaks at $1604 \mathrm{~cm}^{-1}$ and $1336 \mathrm{~cm}^{-1}$, corresponding to ordered carbon atom, G-band and disordered carbon atom, and D-band, respectively, as a result of first-order Raman scattering. These peaks were associated with both CNTs and graphite [7]; the CNTs quality can be estimated from intensity ratio of D-band $\left(I_{\mathrm{D}}\right)$ and G-band $\left(I_{\mathrm{G}}\right)[6$, $8,9]$. Intensity ratio of these peaks, $I_{\mathrm{G}} / I_{\mathrm{D}}$, is calculated to be 0.98 , which indicates that the graphitized material has defects [5]. The high intensity of D-band arises from the distorted carbon atoms on the surface and edges as well as $\mathrm{sp}^{3}$ bonding which serve as impurity [1]. The small peaks at $135.81 \mathrm{~cm}^{-1}$ and $240.29 \mathrm{~cm}^{-1}$ are described as radial breathing mode (RBM), associated with SWCNTS while the peak at $519.88 \mathrm{~cm}^{-1}$ represents signal from $\mathrm{Si}$ substrate as depicted in Figure 1(b). The diameter, $d$, of the SWCNTs is estimated from the RBM peak position, $\omega$ as $d=248\left(\mathrm{~cm}^{-1}\right)(\mathrm{nm}) / \omega\left(\mathrm{cm}^{-1}\right)$ [10], which yield diameters of about $1.83 \mathrm{~nm}$ and $1.03 \mathrm{~nm}$, respectively. Figures $1(\mathrm{a})$ and $1(\mathrm{~b})$ show evidence that the obtained sample is a mixture of both single- and multiwalled CNTs.

Figures 2(a) and 2(b) show FESEM morphological images of CNTs grown on silicon substrate, obtained from plasma catalytic decomposition of polyethylene. The CNTs consist of SWCNTs and MWCNTs which we could confirm due to the presence of RBM [7]. CNTs diameters are in the range of 1.03-25.00 nm and are formed in entangled bundles due to catalyst nanoparticles movement under microwave irradiation when carbon species diffuses across substrate. The CNTs are elongated and measured about $0.85 \mu \mathrm{m}$. At high magnification, sample shows the CNTs are made up of entangled individual CNTs. The irregularities in CNTs shape and diameter are attributed to high D-band level. The arrows indicate the presence of catalyst embedded within the tube walls which is one of the characteristics of most CNTs synthesized in microwave oven $[1,11]$. The encapsulated catalyst within the tubes was due to capillarity action perhaps as a result of interaction between the catalyst and substrate [1]. Figures 2(c) and 2(d) show HRTEM images which indicate CNTs are graphitized in conformity with Raman spectra and FESEM results. From these images the interlayer spacing between CNTs lattice was measured to be in the range of $3.2 \AA$ to $4.2 \AA$. Based on the EDX analysis and TGA result, the percentage of elementary composition in the sample was revealed. Carbon is the dominant element while oxygen percentage is negligible. The TGA result shown in Figure 3 indicates a rapid oxidation of CNTs from $540^{\circ} \mathrm{C}$ to $640^{\circ} \mathrm{C}$ with $90 \%$ sample weight loss; the sharp peak observed from DTGA result corresponds to this region. At $640^{\circ} \mathrm{C}$ the sample contains $2 \%$ residue which continues to drop gradually to $1.3 \%$ at $1000^{\circ} \mathrm{C}$. The purity level of 


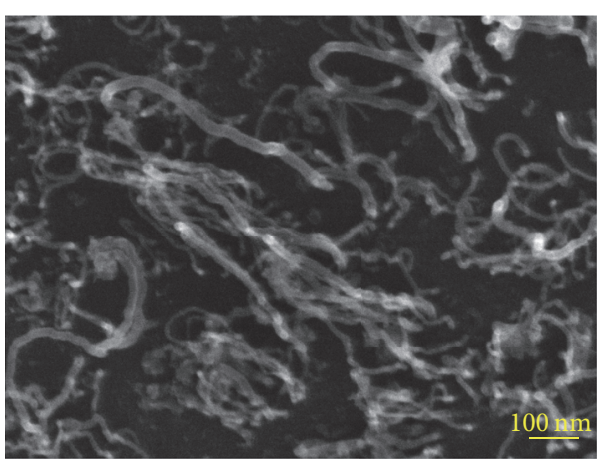

(a)

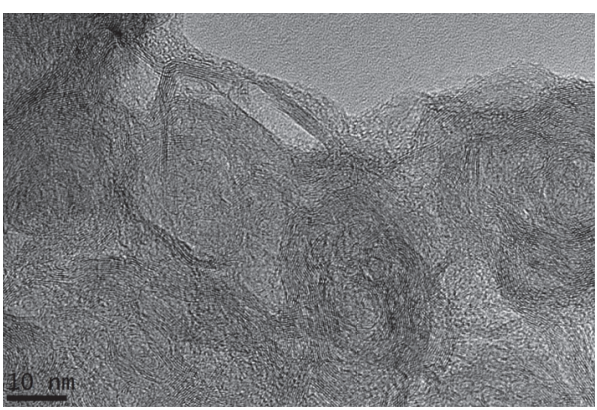

(c)

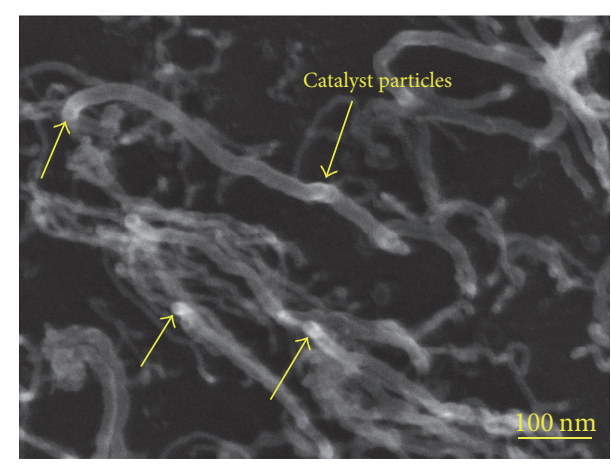

(b)

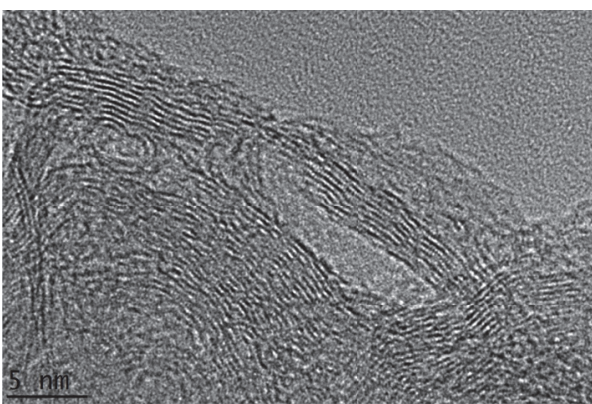

(d)

FIGURE 2: (a)-(b) FESEM images of CNTs at different magnification (arrows pointing to catalyst particles). (c)-(d) HRTEM images of CNTs at different magnification.

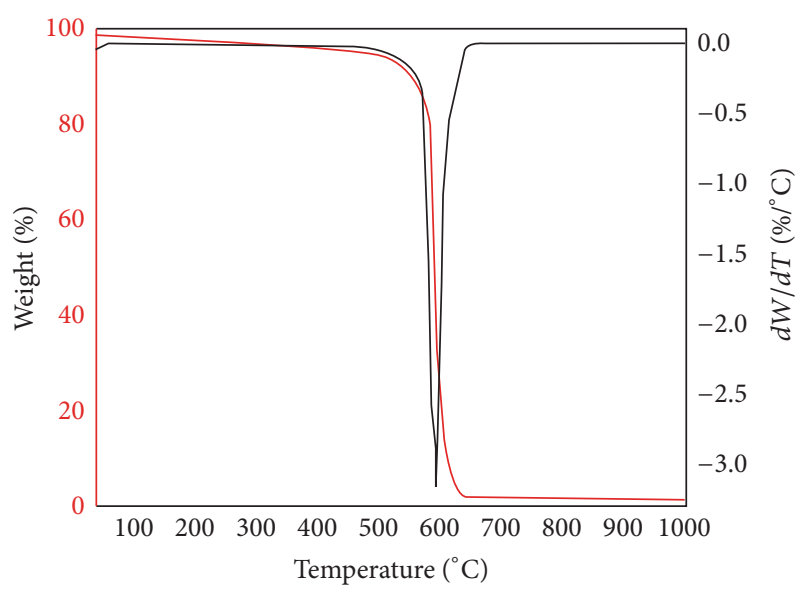

Figure 3: TGA and DTGA result of as-synthesized CNTs.

the CNTs obtained via EDX is depicted in Table 1. From these results we could conclude that the growth mechanism of CNTs via microwave irradiation is similar to the CVD method in which the carbon atoms dissolve in catalyst particles until the dissolved materials reach saturation which results in CNTs growth. Decomposition of polyethylene molecules to individual carbon atoms as a result of volumetric heating via plasma induced by microwave irradiation [5] would be the main difference in this technique with CVD.
TABLE 1: EDX of the CNTs.

\begin{tabular}{lcc}
\hline Element & Weight (\%) & Atomic (\%) \\
\hline $\mathrm{C}(\mathrm{K})$ & 99.86 & 99.90 \\
$\mathrm{~N}(\mathrm{~K})$ & 0.00 & 0.00 \\
$\mathrm{O}(\mathrm{K})$ & 0.10 & 0.08 \\
$\mathrm{Si}(\mathrm{K})$ & 0.02 & 0.00 \\
$\mathrm{Fe}(\mathrm{K})$ & 0.00 & 0.00 \\
\hline
\end{tabular}

\section{Conclusions}

This study has proven to be successful within a short period of time (1 hour). It offers an alternative technique of synthesizing CNTs at low cost using efficient procedures which can be scaled up for mass production. A mixture of SWCNTs and MWCNTs was obtained, similar to most chemical vapor deposition techniques. Raman spectroscopy and FESEM analysis reveal CNTs produced are in diameter range of 1.03$25.00 \mathrm{~nm}$ with length of about $0.85 \mu \mathrm{m}$. HRTEM confirms that CNTs are graphitic in structure. EDX analysis shows that CNTs are produced with about $98 \%$ carbon purity. For fast synthesis of CNTs using commercial microwave oven the presence of plasma, carbon source, and catalyst is necessary.

\section{Competing Interests}

The authors declare that they have no competing interests. 


\section{Acknowledgments}

The authors would like to thank Universiti Putra Malaysia (Grant code: GP-IPS/2014/9438710) for their financial support.

\section{References}

[1] R. Bajpai and H. D. Wagner, "Fast growth of carbon nanotubes using a microwave oven," Carbon, vol. 82, pp. 327-336, 2015.

[2] N. M. Mubarak, J. N. Sahu, E. C. Abdullah, N. S. Jayakumar, and P. Ganesan, "Single stage production of carbon nanotubes using microwave technology," Diamond and Related Materials, vol. 48, pp. 52-59, 2014.

[3] M. Hotta, M. Hayashi, M. T. Lanagan, D. K. Agrawal, and K. Nagata, "Complex permittivity of graphite, carbon black and coal powders in the ranges of X-band frequencies (8.2 to 12.4 $\mathrm{GHz}$ ) and between 1 and $10 \mathrm{GHz}$," ISIJ International, vol. 51, no. 11, pp. 1766-1772, 2011.

[4] J. A. Menéndez, A. Arenillas, B. Fidalgo et al., "Microwave heating processes involving carbon materials," Fuel Processing Technology, vol. 91, no. 1, pp. 1-8, 2010.

[5] P. Hojati-Talemi and G. P. Simon, "Preparation of graphene nanowalls by a simple microwave-based method," Carbon, vol. 48, no. 14, pp. 3993-4000, 2010.

[6] Z. Yunusa, S. Abdul Rashid, M. N. Hamidon, S. Hafiz, I. Ismail, and S. Rahmanian, "Synthesis of Y-tip graphitic nanoribbons from alcohol catalytic chemical vapor deposition on piezoelectric substrate," Journal of Nanomaterials, vol. 2015, Article ID 754768, 7 pages, 2015.

[7] M. S. Dresselhaus, G. Dresselhaus, A. Jorio, A. G. Souza Filho, and R. Saito, "Raman spectroscopy on isolated single wall carbon nanotubes," Carbon, vol. 40, no. 12, pp. 2043-2061, 2002.

[8] W.-W. Liu, S.-P. Chai, A. R. Mohamed, and U. Hashim, "Synthesis and characterization of graphene and carbon nanotubes: a review on the past and recent developments," Journal of Industrial and Engineering Chemistry, vol. 20, no. 4, pp. 11711185, 2014.

[9] C. Herrero-Latorre, J. Álvarez-Méndez, J. Barciela-García, S. García-Martín, and R. M. Peña-Crecente, "Characterization of carbon nanotubes and analytical methods for their determination in environmental and biological samples: a review," Analytica Chimica Acta, vol. 853, no. 1, pp. 77-94, 2015.

[10] A. B. Suriani, A. A. Azira, S. F. Nik, R. Md Nor, and M. Rusop, "Synthesis of vertically aligned carbon nanotubes using natural palm oil as carbon precursor," Materials Letters, vol. 63, no. 30, pp. 2704-2706, 2009.

[11] Z. Liu, J. Wang, V. Kushvaha et al., "Poptube approach for ultrafast carbon nanotube growth," Chemical Communications, vol. 47, no. 35, pp. 9912-9914, 2011. 

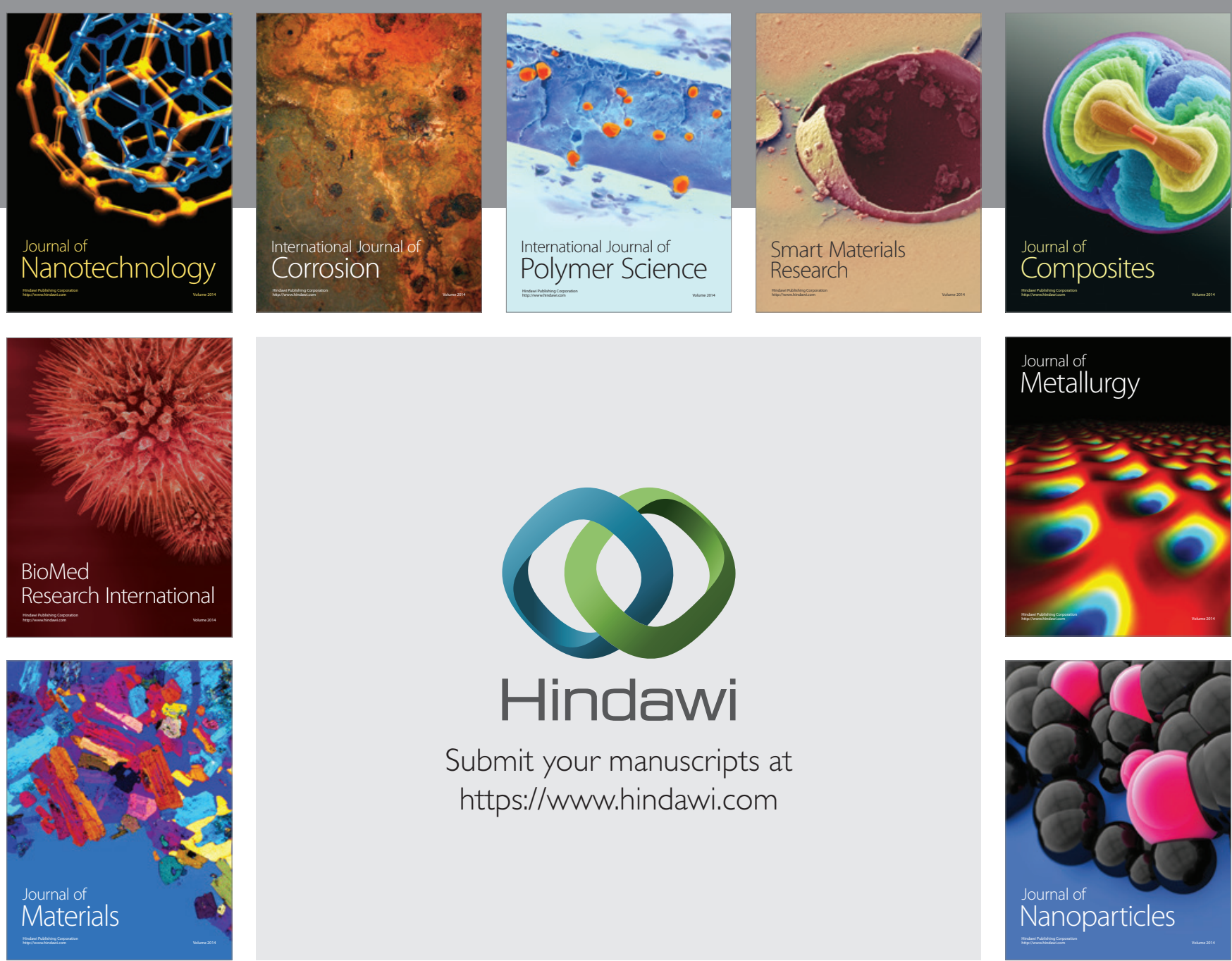

\section{Hindawi}

Submit your manuscripts at

https://www.hindawi.com

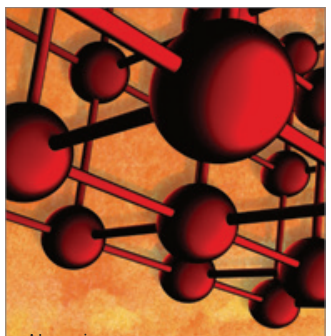

Materials Science and Engineering
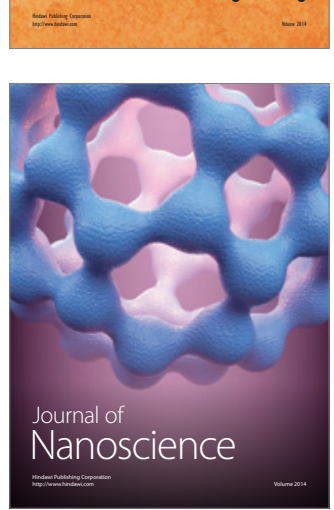
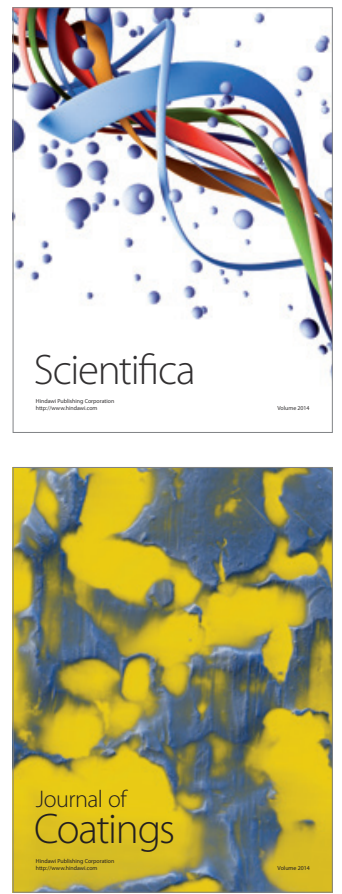
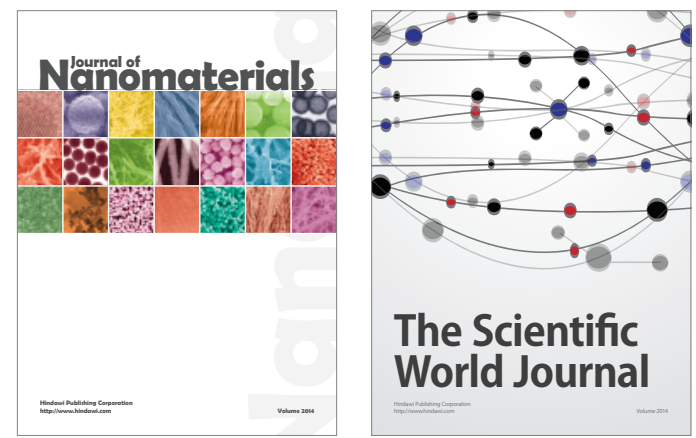

The Scientific World Journal
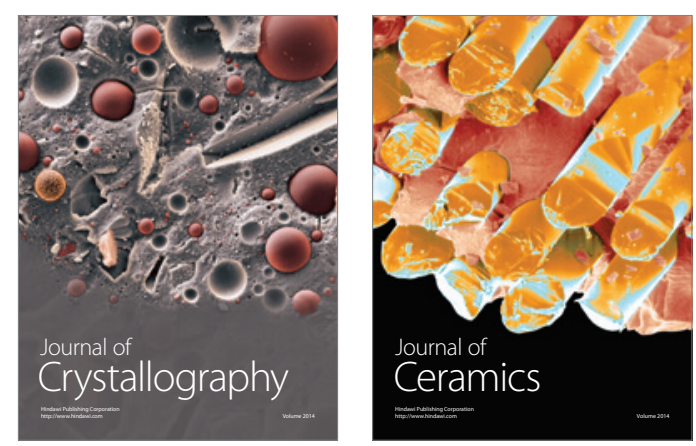
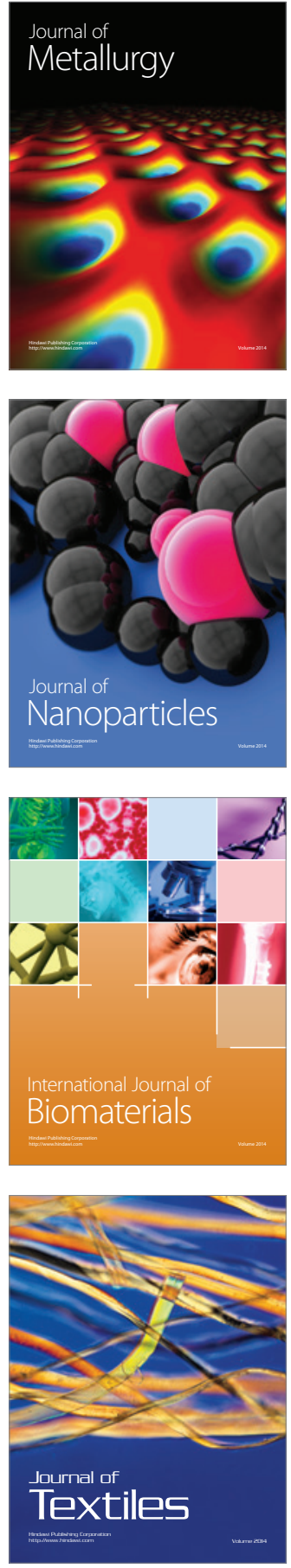